\title{
Perspectiva da educação somática no currículo do Ensino Básico: dança e relações de poder no corpo
}

The somatic education perspective in the curriculum of primary and secondary school: dance and power relations in the body

Maria Fonseca Falkembach ${ }^{1}$ 


\section{Resumo}

O processo recente de inserção da dança como componente curricular obrigatório no ensino de Arte na escola apresenta tensões que evidenciam desalinho entre os saberes da dança e os saberes escolares. O texto reflete sobre os problemas enfrentados por uma professora de dança, cuja prática artística emerge da perspectiva da educação somática, ao compor o currículo em uma escola pública no Rio Grande do Sul. Os dados foram produzidos em uma pesquisa com base na Etnografia Performativa e analisados desde as ferramentas teóricas de Michel Foucault. Evidencia que o currículo é campo de luta política e descreve como a perspectiva da educação somática ocupa lugar nas relações de poder na escola.

Palavras-chave: Pedagogia da dança; educação somática; escola; currículo

\section{Abstract}

Dance as a mandatory discipline presents tensions regarding the mismatch between dance knowledge and other hegemonic knowledge at school. This text discusses problems faced by a dance teacher during the establishment of a curriculum for the discipline of Arts in a Southern Brazilian school. From the perspective of somatic education, the teacher's artistic practice challenges the pre-established curriculum. The Performative Ethnography methodology provided research data and the analysis was made with Michel Foucault's theoretical tools. This article shows the curriculum as a field of political dispute and describes how somatic education occupies its place at school amongst power relations.

Keywords: Dance education; somatic education; school; curriculum

E-ISSN: 2358.6958

\footnotetext{
1 Profa. Dra. Universidade Federal de Pelotas (UFPe). Professora convidada da Maestria Profesinoal en Danza da Escuel de Danza da Universidad Nacional de Costa Rica desde 2007. Coordenadora e coreógrafa-diretora do grupo Tatá de Dança-Teatro. mariafalkembach@gmail.com
} 
O presente texto discute parte dos dados produzidos em pesquisa sobre o ensino de dança como componente curricular de Arte, em escolas no Rio Grande do $\mathrm{Sul}^{2}$. Nessa pesquisa, acompanhei seis professoras de dança, por um período médio de duas semanas cada, em seis diferentes escolas, de três cidades, no segundo semestre de 2015. Este artigo foca a discussão sobre a possibilidade (e dificuldades) da presença da perspectiva da educação somática na composição do currículo, a partir da análise das aulas de uma das professoras, aqui denominada Adriana (nome fictício, criado para resguardar o seu anonimato).

A investigação construiu-se por via de uma metodologia que articula elementos da Etnografia Performativa (Pineau, 2013), do método Cartográfico (Kastrup; Passos, 2013) e da Genética Teatral (Fernandes, 2013). Assim, realizei uma observação participante, na qual em alguns casos participei ativamente nas aulas observadas. Todas as observações foram registradas em caderno de notas, assim como em gravação em áudio e vídeo. Ainda, realizei entrevistas com as professoras e com um profissional da equipe diretiva de cada escola.

Ao longo da pesquisa identifiquei que as seis professoras trabalham com práticas na perspectiva da educação somática. Práticas que levam em conta a sensação como modo de conhecimento e cujo modo de conhecer se constitui na percepção em primeira pessoa: observação miúda de cada um sobre seu corpo em movimento (Rosa, 2016b). Tatiana da Rosa aponta a necessidade do reconhecimento desse saber específico, importante no fazer poético e pedagógico da dança, sem o qual, segundo a autora, "[...] a arte, e muito especialmente as artes vivas do teatro, da dança e da performance não podem pertencer senão ao reino da afasia, desempoderadas" (Rosa, 2016b, p. 2). A autora aposta na relevância do processo de conexão com as sensações, que também chama de escuta das sensações, como conhecimento compartilhável. Um conhecimento daquilo que ultrapassa o nomeável. "A sensação é reverberável, mesmo que de maneira incompleta (Gil, 2004). Se a permito (ser e ver), ela é volume e visível no corpo, assim tem se apostado na dança. Ela é reverberável como volume, sensação mesma e como memória" (Rosa, 2016b, p. 4-5).

Percebi, nas aulas das professoras, vestígios da relação de fusão entre dança e educação somática, por exemplo, quando as aulas não começam em frente ao espelho, mas começam no chão. Ou, quando a prática é feita de olhos fechados. Portanto, quando as aulas não começam com uma postura construída a partir de um olhar externo, mas com base na sensação de cada indivíduo sobre seu corpo, sobre as conexões entre as articulações, por via da percepção de tensões e estrutura particular do corpo de cada um, buscando deixar as conexões livres para produzir mobilidade. Identifiquei sinais dessa fusão quando o estado de dança é construído a partir da escuta, em vez de a partir de uma sequência de movimentos copiados e repetidos.

\footnotetext{
2 A dança como componente curricular obrigatório de Arte na educação básica, no Brasil, é um fato recente. Em 1998, são criados os Parâmetros Curriculares Nacionais - PCNs (Brasil, 1997), que indicam a dança, as artes visuais, o teatro e a música como as linguagens do componente curricular obrigatório de Arte. Porém, somente em 2016 foi publicada a Lei no 13.278/16 (Brasil, 2016) que institui tal obrigatoriedade, ao alterar o $\$ 6^{\circ}$ do art. 26 da Lei nº 9.394 de 1996 (Brasil, 1996). Essa última, lei que fixa as diretrizes e bases da educação nacional, estabelecia como obrigatoriedade o ensino de arte de modo abrangente. O novo documento do governo federal, que substitui os PCNs e propõe um currículo comum para todo o território brasileiro, a Base Nacional Comum Curricular - BNCC (Brasil, 2017), estabelece a dança como uma das linguagens da área de Arte.
} 
Embora eu considere que essas premissas são constituintes da educação somática, não posso precisar sempre se emergem da experiência das professoras com alguma técnica somática ou com um determinado modo de fazer dança. Tanto porque essas práticas se fundem numa abordagem que contempla essas premissas, como porque não é sempre que as professoras conseguem localizar exatamente as referências das práticas que desenvolvem. Aquilo que fazem é determinado pelas condições da história de cada uma e o modo específico de arranjar suas experiências: agregando e excluindo, repetindo e interrompendo, lembrando e esquecendo princípios, operações, exercícios e atitudes. Suas práticas na escola são efeito de sua formação multifacetada na relação com o contexto da escola (Souza, 2015). De qualquer forma, de um modo geral, quando relatam suas experiências, grande parte das vivências nessa perspectiva foram proporcionadas pelos Cursos de Licenciatura em Dança pelos quais passaram.

Rosa (2016a) nos mostra que o abordar somático do corpo é componente dos currículos dos cursos de graduação em Dança no Rio Grande do Sul, sendo que todas as professoras participantes desta pesquisa foram graduadas em dança em Universidades desse estado. De fato, o importante aqui não é estabelecer origem, mas observar que as práticas de ensino de dança nas escolas em que desenvolvi a pesquisa estão contaminadas pelo que escolhi chamar de perspectiva da educação somática. Escolhi chamar assim por dois motivos, sendo o primeiro para marcar o lugar desse discurso outro, no ano de 2009 ainda considerado, por Fortin et al. (2009), marginal em relação ao discurso dominante da dança que valoriza um corpo ideal e fantasioso. A segunda razão é que percebo a tendência de pesquisas em dança que trazem questões relacionadas à consciência corporal e à escuta percorrerem o caminho, mesmo que transversal, no campo da educação somática. Um campo, portanto, que se solidifica cada vez mais. Mais do que isso, há o crescimento da pesquisa interessada no material somático utilizado em aulas de dança. Fortin, por exemplo, justifica uma pesquisa colaborativa desenvolvida com um grupo internacional que visa refletir sobre como a educação somática é integrada em aulas de dança contemporânea, dizendo que "[...] há muita menção da influência da somática no ensino de dança, mas pouca pesquisa documentando como isso concretamente ocorre" (Fortin, 2002, p. 132) ${ }^{3}$.

\section{Abordagem somática e dança como arte}

Adriana era professora de uma escola estadual. Começou a ministrar aula nesta escola em 2014, mesmo ano em que se graduou. Quando observei suas aulas, ela estava há um ano trabalhando na escola. Depois da pesquisa, começou a fazer mestrado e se exonerou. Ministrava aulas para o 6ㅇ e 0 7음 ano do ensino fundamental e para o $1^{\circ}$ ano do ensino médio. Com três turmas de cada ano, completava a carga horária de 20 horas de trabalho semanais e tinha cerca de 240 alunos. As turmas do

\footnotetext{
3 No original, em inglês: "there are numerous claims about the influences of somatics on dance teaching, but little research documenting how this concretely occurs" (Fortin, 2002, p. 132) (Tradução nossa). Fortin também traz como exemplo a pesquisa de um grupo de dois professores e dois praticantes de somática, na Austrália, que escreveu um manual para professores de dança descrevendo os benefícios de processos somáticos no treino de dança, após pesquisa de dois anos explorando a integração de alguns materiais somáticos em aulas de dança contemporânea.
} 
ensino fundamental têm cerca de 30 alunos por turma. Participei de uma aula do ensino médio com apenas cinco alunos, mas são cerca de 20 por turma. Acompanhei a tensão em que vivia a professora, produzida pelas exigências da direção da escola quanto ao conteúdo que deveria ser ministrado, que deveria seguir o plano de ensino do currículo de artes visuais.

Adriana foi, portanto, produzindo um currículo que fazia pontes e transposições das artes visuais para práticas de dança, seguindo o conteúdo de história da arte. Sua formação está marcada por dança contemporânea, práticas de educação somática e estudos labanianos. Aqui, apresento uma reflexão com base em sua inquietude devido sua dificuldade para trabalhar com educação somática: uma trama entre a estrutura inadequada da sala, o "compromisso com o conteúdo" e a falta de disponibilidade dos alunos.

O chão da sala de dança da escola de Adriana é frio (de piso cerâmico), escorregadio e úmido. Quando Jussara Miller descreve seu trabalho com a técnica Klauss Vianna, ela traz a imagem do pé descalço "no chão de madeira da sala de aula e do palco" (Miller, 2012, p. 13). Tocar o chão, deitar-se no chão com o corpo "em baixo tônus para propiciar micro-ajustes posturais" (Rosa, 2016b, p. 9), é operação inerente a grande parte das técnicas somáticas. O deitar-se no chão é, também, a ideia de uma possibilidade de retorno ao antes de caminhar, antes do corpo tornar-se estruturado para mover-se verticalmente. As técnicas Bartenieff e a Ideocinese, por exemplo, fazem associações entre o desenvolvimento ontogenético e filogenético que passa, também, por sair do chão e aprender a caminhar ou tornar-se um animal bípede, respectivamente (Todd, 1937, p. 13-23). Portanto, contar com o modo de conhecimento somático no currículo, pressupõe deitar-se no chão.

Entretanto, as tensões relacionadas com o espaço vão além da negociação por um espaço apropriado na estrutura deficitária da escola pública brasileira. Na aula de dança, os corpos são distribuídos no espaço vazio, sem a segurança do comportamento naturalizado nas classes e cadeiras de uma sala de aula tradicional. Comportamento esse, produzido por relações materializadas pelo enquadramento classificatório e hierárquico, correspondente à operação de vigilância da tecnologia disciplinar (Fuão, 2015).

Mesmo com as dificuldades espaciais, Adriana explica que consegue desenvolver práticas somáticas com os alunos do $1^{\circ}$ ano do ensino médio porque o conteúdo previsto no currículo desse ano escolar é a arte contemporânea. Nessas aulas, Adriana parece chegar mais perto do que imagina que deve ser uma prática de dança na escola. Segundo Adriana, "a questão da consciência corporal e da organização do corpo" é o que a orienta na sua prática de dança, tanto como professora quanto como bailarina4 (Dossiê Adriana, 2016, p. 27). Ela fala de uma organização corporal da educação somática, que organiza as articulações e a respiração na produção de um corpo engajado.

Nas aulas com os alunos do 10 ano ela também consegue integrar os "conteúdos" e a prática de dança. Até mesmo porque o modo de compreensão dos conteúdos da dança contemporânea passa pela percepção mobilizada pela experiência com as técnicas somáticas.

\footnotetext{
${ }^{4}$ Adriana relata que antes de fazer o curso de Graduação em Dança, participou de "um grupo de estudos e experimentação em Laban", que se encontrava duas vezes por semana. Nesse grupo teve acesso à prática e à leitura sobre os estudos de Laban e de educação somática (Dossiê Adriana, 2016, p. 45).
} 
As práticas somáticas, que trabalham para um corpo disponível para a pluralidade do movimento, dão subsídios à dança contemporânea e sua diversidade inerente (Miller, 2012). A busca da consciência do movimento - do corpo que compreende o movimento - é o tipo de preparação para as necessidades da dança contemporânea. O processo que produz essa consciência, que é corporal, é fornecido pela prática das técnicas somáticas. Por via dessa perspectiva, dançarinos contemporâneos são encorajados a serem protagonistas de sua dança e de si mesmos, em vez de meros corpos dóceis dançantes (Fortin et al., 2002).

Entendo que a questão aqui envolvida é sobre um modo de conhecer, é uma questão epistemológica (Fernandes, 2015; Domenici, 2010). A professora Adriana fala disso quando diz que as práticas somáticas trabalham o estado de percepção necessário para a compreensão da teoria de Laban. Ela comenta:

Então eu acabo fazendo atividades no campo da educação somática, exercícios, movimentos, com o $1^{\circ}$ ano... uso da bolinha... e acho que com essa sensibilização eles acessam muito melhor o conteúdo... que essa diferença entre o peso forte e o peso leve significa um tônus. Que que é aceleração? Que que é uma nuance da aceleração. Acelerado não é uma permanência, tu tens que sair do menos pro mais, é a diferença que torna uma coisa acelerada e uma coisa lenta. Então a educação somática coloca eles nesse estado de percepção. (Dossiê Adriana, 2016, p. 47-48)

O conteúdo é, dessa forma, produzido pelo modo como a professora conduz esse mesmo conteúdo. Uma coisa é o conhecimento sobre a diferença entre peso forte e peso leve que se pode ter lendo um texto; outra coisa, fazendo um jogo e colocando o corpo a viver essa diferença; outra, repetindo movimentos de uma coreografia que apresente essa diferença. Outra coisa, ainda, é perceber-se nessa diferença, é identificar a fisicalidade e as sensações dessa diferença. Assim, o conteúdo "diferença entre peso forte e peso leve" em cada uma dessas quatro abordagens, em cada um desses modos de conhecer, é um conteúdo diverso - o objeto e o modo de conhecer se autodeterminam. Aqui, o modo como a professora Adriana desenvolve esse conteúdo (ela fala em acessar o conteúdo) se aproxima do modo de operar da noção (Icle, 2011), elemento que só tem existência no corpo em prática de criação. Adriana está interessada naquilo que é produzido pelo corpo num estado de concentração e percepção que ela denomina sensibilização. A noção, nesse caso, irrompe no estado de sensibilização. A sensibilização não implica apenas a percepção proprioceptiva, mas a ênfase na propriocepção possibilita um estado que integra as diferentes dimensões do pensamento - imaginário, físico, racional, emocional e poético.

A questão sobre o modo de conhecer é uma das pautas das pesquisas no campo da educação somática, que seguem o caminho interdisciplinar da fundação de todas as técnicas que compõem o campo. A partir da perspectiva de pesquisas sobre a cognição humana, Domenici escreve que "[...] a maneira como se experiencia o mundo interfere determinantemente no que se conhece" (Domenici, 2010, p. 72). Na escola, o modo como se experiencia o mundo está intrincado com os modos de aprender e de ensinar, que produzem o objeto que se conhece e se ensina. Também se ensina o modo de aprender. 
A perspectiva foucaultiana, que entende a prática de ensino como governo (de si e do outro), ressalta o papel da conduta da professora na constituição da prática. Conduta que é produzida nas relações de saber-poder aí inerentes, na relação entre professora, alunos e escola.

A diferença da atuação da professora nas turmas de $6^{\circ}$ e $7^{\circ}$ ano do ensino fundamental e nas turmas de $1^{\circ}$ ano de ensino médio revela a complexidade desse processo, que produz, ao mesmo tempo: o modo de ensinar, o modo de aprender e os objetos a conhecer, isto é, o currículo. Conforme Andrea Souza (2015, p. 46), “[...] o currículo não se faz somente previamente ao ato de ensinar (dança), mas também no momento das aulas, nas relações, disputas e negociações no cotidiano escolar".

Nas aulas com o 6 e 7을 anos do ensino fundamental, a necessidade de seguir um tipo de conteúdo (estabelecido pela história cronológica das artes visuais) desvia a professora Adriana do caminho que parte do corpo que compreende (da consciência corporal). Somado a isso, ela enfrenta a dificuldade de instalar a abordagem da educação somática em grupos em que as relações são pautadas por atitudes violentas e de deboche, como ocorre nessas turmas. Dessa forma, as escolhas sobre o que ensinar para essas turmas estão mais implicadas naquilo que é possível do que naquilo que a professora considera significativo.

O mandato que Adriana se coloca, de desenvolver conteúdos e, ao mesmo tempo, de trabalhar a dança desde a perspectiva da arte, fornece elementos para contribuir com questões que o campo de estudos do currículo tem se feito. A dança, no processo recente de ser colocada como componente curricular obrigatória no ensino de Arte na escola, de certa forma, faz o movimento contrário da perspectiva que pensa o currículo de modo alargado, isto é, fora da escola. Antes de ser parte obrigatória do ensino, as práticas de ensino de dança compunham o que se compreende como currículo alargado.

Aprendemos dança em diferentes instâncias culturais (escola, universidade, mídia, centros culturais ou de tradição, academias, vídeos, dentre tantos outros) e as noções de corpo, gênero, sociedade e educação são também diversas; afirmo então que cada dança (ensinada/aprendida) carrega currículos particulares que ensinam formas de ser e estar no mundo. (Souza, 2015, p. 48)

No momento em que passa a fazer parte da educação escolarizada, a dança se vê, em muitos casos, constrita a noções de currículo tradicionais ou conteudistas. Tal situação pode restringir consideravelmente a construção de processos criativos.

Por outro lado, quando a dança se torna obrigatória, isto é, quando há uma massificação da dança ${ }^{5}$, o rigor sobre as escolhas que definem o currículo aumenta, pois "o que" e "por que" se ensina dança precisam dar conta da multiplicidade dos corpos-sujeitos. Quando todos e todas devem fazer dança o poder político das escolhas fica evidenciado, pois as escolhas sobre o que vai fazer parte de um currículo estão implicadas com o que eles e elas devem se tornar.

${ }_{5}^{5}$ Silva aponta que o currículo como objeto de estudo aparece nos anos 1920, num processo de massificação da escolarização: naquele momento o currículo é "[...] a especificação precisa de objetivos, procedimentos e métodos para a obtenção de resultados que possam ser precisamente mensurados" (Silva, 2007, p. 12). 
Afinal, um currículo busca precisamente modificar as pessoas que vão 'seguir' aquele currículo. [...] [A]s teorias do currículo deduzem o tipo de conhecimento considerado importante justamente a partir de descrições sobre o tipo de pessoa que elas consideram ideal. Qual é o tipo de ser humano desejável para um determinado tipo de sociedade? (Silva, 2007, p. 15)

Com os alunos do ensino médio, Adriana consegue estabelecer uma relação e um espaço no qual pode conduzir sua proposta de modo parecido com sua prática de dança fora da escola (em espaços de pesquisa e criação artística). Suas escolhas para a prática curricular com esses alunos estão próximas das escolhas que faz na construção de seus processos de criação, na sua experiência de dança como arte.

Nesse sentido, a maneira como Adriana lida com a prática da dança na escola me faz pensar sobre diferentes modos de conceber a "dança como arte", ou dança profissional - que se cruzam no mundo da dança fora e dentro da escola. Trago isso para problematizar o conceito de "dança como arte", de Smith-Autard (2002; 2004), difundido no mundo da dança educação, e base do currículo de dança nas escolas do Reino Unido.

O midway model, ou a abordagem da "dança como arte", propõe o meio do caminho entre a dança educativa e a dança profissional na construção de um currículo equilibrado. É necessário, aqui, levar em conta que essa polarização entre dança educativa e dança profissional foi produzida no contexto britânico ao longo da década de 1970. É parte de um conjunto de discussões e proposições: sobre o papel da dança na escola; sobre a curricularização da dança através de sistematização de conteúdos e objetivos claros; e sobre a obra de arte com um objeto a ser conhecido (Gehres, 2008, p. 23). Smith-Autard se refere à dança educativa como uma abordagem derivada das ideias de Rudolf Laban desenvolvidas entre o final da década de 1940 e o início da década de 1970. Conforme a autora,

A principal característica do modelo 'educacional' foi a ênfase no processo de dançar e sua contribuição afetiva/experiencial ao desenvolvimento integral do participante, como um ser de movimento/sentimento. Considerava-se os benefícios da expressão de sentimentos pessoais e pelo movimento, a partir de vários estímulos, contribuição importante para o desenvolvimento geral da personalidade. (Smith-Autard, 2002, p. 4). ${ }^{6}$

O modelo oposto ao educacional, denominado profissional, é uma extensão do pensamento sobre dança nas escolas secundárias e educação superior nas décadas de 1960 e 1970, que apresentava como principal objetivo

[...] produzir dançarinos altamente qualificados e obras de dança cênica para apresentação ao público. Esses resultados eram considerados como veículos através dos quais uma gama de habilidades em dança, que constituem qualquer estilo, poderia ser exibida. O conteúdo desses cursos era baseado em um conjunto de habilidades prescrito por cada estilo de dança a ser estudado, por exemplo, Graham, Cunningham, balé clássico ou jazz (Smith-Autard, 2002, p. 4). ${ }^{7}$

\footnotetext{
${ }^{6}$ Em inglês, no original: The essential characteristic of his 'educational' model was its emphasis on the process of dancing and its affective/experiential contribution to the participant's overall development as a moving/feeling being. The benefits of feeling personal expressive significance in movement outcomes derived from various stimuli were considered important contributions to the all-round development of the personality (Smith-Autard, 2002, p. 4). (Tradução nossa)

${ }^{7}$ Em inglês, no original: The main aim was to produce highly skilled dancers and theatrically defined dance products for presentation to audiences. Such dance outcomes would be considered as vehicles through which the range of dance skills constituting any one style could be exhibited. The content of such courses was an already-defined set of dance skills in the style of dance being studied, e.g. Graham, Cunningham, ballet or jazz (Smith-Autard, 2002, p. 4). (Tradução nossa)
} 
É implícito no midway model que seriam os elementos da dança profissional que trariam o caráter de arte para a dança que se faz na escola. Tais elementos são descritos com a ênfase: no produto; no conhecimento da dança cênica como modelo; em metas objetivas (por exemplo, corpos treinados); nos conteúdos com base em técnicas de dança definidas por estilo; no ensino diretivo (professora como mestre e aluno como pupilo). A dança educativa seria a outra ponta a ser equilibrada, responsável pelo caráter de educação, cujos elementos constituintes seriam a ênfase: no processo; no desenvolvimento da criatividade, imaginação e individualidade; na experiência subjetiva; nos conteúdos com base em um conjunto de princípios do movimento; na resolução de problemas (professora como guia e aluno com o agente de sua aprendizagem) (Smith-Autard, 2002, p. 6).

Porém, a experiência em dança da Adriana nos mostra outra "dança como arte", que passa por um modo de conhecimento e de criação carregado da perspectiva sobre corpo e movimento que a educação somática tem emprestado à dança contemporânea. Uma "dança como arte" mais ligada à cultura da nova dança/release thecnique/ contato improvisação (Rosa, 2016a). Em oposição ao que apresenta o midway model, o caráter de arte da dança da Adriana estaria mais próximo dos modelos que trazem a ênfase no processo e na experiência subjetiva, por exemplo, visto que boa parte da dança cênica contemporânea trabalha com esses princípios. Essa outra "dança como arte" está interessada no desenvolvimento de um estado de percepção para a criação, na disponibilidade e atenção do corpo necessárias para a criação em dança.

A sensibilização que Adriana almeja e a partir da qual aborda o processo de ensino-aprendizagem, se desloca da abordagem com ênfase no aluno, no sentido que é dado para a produção de um aluno autônomo, que aprende a partir da resolução de problemas, como no caso do midway model. Ela propõe uma abordagem que leve em conta a percepção em primeira pessoa, em que a professora conduz o aluno a um estado específico de percepção.

A experiência com Adriana mostra que, definitivamente, estabelecer um currículo de dança na escola não é apenas listar uma sequência de assuntos, ou técnicas, estilos, passos, ou ainda estruturas do movimento. Pelo contrário, o que identifiquei pela observação do trabalho da Adriana, e sua angústia na elaboração do currículo, é que isso implica também construir um modo de conhecer que passa, para ela, pela consciência corporal. No seu caso, a impossibilidade de construir esse tipo de currículo produz angústia, porque o sentido de fazer dança fica vazio - a prática deixa de ser dança.

\section{O poder no corpo e o poder do corpo}

As escolhas da professora Adriana para construir o currículo, isto é, suas escolhas para estabelecer "o que eles ou elas devem ser" (Silva, 2007, p. 15) é congruente com suas escolhas no seu próprio caminho de tornar-se parte do processo de constituição de si envolvido no fazer artístico. Então, quando falamos sobre o sentido de dar aula de dança, Adriana conta que o que a move é ver a beleza da relação que os alunos começam a estabelecer com o movimento. Ela destaca, nessa relação, um efeito positivo sobre os alunos, que é a aceitação de si. Segundo a professora, a consciência corporal desenvolvida em aula contribui com a relação de cada um com seu próprio corpo, que começa pela questão postural. 
E... quando eles são mais velhos acho que tem também essa coisa da relação do próprio corpo, de ser meio envergonhado, de ser meio desengonçado. E de eles começarem a se aceitar e se melhorar, também. Porque às vezes a questão de ser desengonçado é só uma questão de organizar a coluna, de tá atento ao espaço, então tem umas percepções que vão melhorando, eles vão se aceitando mais. (Dossiê Adriana, 2016, p. 30)

A relação entre consciência corporal e aceitar a si mesmo é um enunciado do discurso que compõe a abordagem somática. Mas por que esse trabalho faz com que comecemos a nos aceitar mais? O que é aceitar-se? Por que esse modo de conhecer a mim mesmo produz aceitação?

Essas perguntas poderiam ter diferentes respostas, prefiro encaminhar respostas através da perspectiva das relações de poder e, assim, continuar no pensamento sobre a organização de um currículo de dança. Vivemos numa sociedade que denominamos sociedade de controle, na qual "os comportamentos de integração e de exclusão social próprios do poder são cada vez mais interiorizados nos próprios sujeitos" (Hardt; Negri, 2010, p. 162). Conforme os autores,

O poder se exerce, agora, por máquinas que organizam diretamente os cérebros (por sistemas de comunicação, de redes de informações, etc.) em direção a um estado de alienação autônoma, partindo do sentido da vida e do desejo de criatividade". (Hardt; Negri, 2010, p. 162)

Esse poder atua sobre o corpo mediante estratégias de produção de necessidades e desejos, as biopolíticas (Foucault, 1979) ${ }^{8}$. Máquinas de capturar e produzir desejos que operam por via de tecnologias como o marketing, a publicidade, o design, tendo a televisão como uma mídia de grande difusão. Nessa rede, padrões de corpo e felicidade idealizados, produzidos com base na imagem (Silva, 2001), são cada vez mais inumanos e improváveis.

Peter Pál Pelbart aborda a relação de poder biopolítica que, no lugar do trabalho psíquico,

[...] faz com que se trabalhe intensamente o corpo, principalmente em duas direções: para que o corpo obedeça a uma espécie de padrão estético das celebridades e para que obedeça a uma certa normatividade 'científica', em relação ao que a ciência diz que é bom para a saúde e as revistas nos transmitem como a perfeição em saúde ou em estética. Ninguém alcança esse padrão ideal, todos precisam trabalhar muito para obedecer minimamente a esses padrões e isso cria uma sensação de insuficiência. Esse corpo não é mais aquele corpo do hostilizado e disciplinado, porque é outro contexto menos militarizado. Não é 'eu obedeço ao professor, ou ao capitão, ou ao dono da empresa'. É 'eu quero ter saúde', 'eu quero ter beleza'. É outra modalidade de exercício de poder que não é por ordem mas por incitamento, por sedução. Então, claro, não é o corpo para a subversão ou a rebelião, é o corpo de uma certa hiperprodução. (Pál Pelbart, 2014, s. p.)

\footnotetext{
8 Foucault identifica que a biopolítica se produz na emergência da população ao mesmo tempo em que a população é especificada pelas ações e estratégias da biopolítica. O objetivo do governo não é governar, "mas melhorar a sorte da população, aumentar sua riqueza, sua duração de vida, sua saúde, etc." (Foucault, 1979, p. 289). "A população aparece, portanto, mais como fim e instrumento do governo que como força do soberano; a população aparece como sujeito de necessidades, de aspirações, mas também como objeto nas mãos do governo; com consciente, frente ao governo, daquilo que ela quer e inconsciente em relação àquilo que se quer que ela faça. $O$ interesse individual - como consciência de cada indivíduo constituinte da população - e o interesse geral como interesse da população, quaisquer que sejam os interesses e as aspirações individuais daqueles que a compõem - constituem o alvo e o instrumento fundamental do governo da população" (Foucault, 1979, p. 289).
} 
Resistir à sedução desse lugar de poder, que produz insuficiência e fracasso passa, portanto, pelo processo de aceitarmos que nunca seremos nada parecidos aos padrões. Esse processo implica em práticas sobre si mesmo, que possibilitam o indivíduo trabalhar na constituição de si: um processo de produção de subjetividade que requer não se acomodar aos consensos e padrões estabelecidos.

Em conversa que Fortin tem com Sylvia Soter, a bailarina brasileira que trabalha com educação somática, com base em sua experiência no Rio de Janeiro, diz que há: “[...] muita pressão para os dançarinos e não dançarinos brasileiros conformarem-se à imagem externa do corpo fornecida pela mídia, sendo seus corpos expostos durante todo o ano ao olhar dos outros em cidades praieiras" (Fortin, 2002, p. 133) ${ }^{9}$. Acredito que viver em uma cidade de praia não seja um fator determinante, pois o corpo está exposto em todo lugar. Mas talvez o imaginário do corpo da praia, da cidade sede da televisão de maior difusão no Brasil seja, sim, determinante. Não cabe a este estudo fazer essa análise, porém considero importante marcar o poder do que Soter chama de "imagem externa do corpo fornecida pela mídia" (Fortin, 2002, p. 133). Segundo a professora brasileira, seu trabalho em aulas para não-dançarinos também se trata de ajudá-los a envelhecer (Fortin, 2002, p. 133).

A busca por aceitar o corpo que é diferente do corpo difundido pelo modelo da bailarina clássica também está presente no mundo da dança fora da escola, daquela dança que ressalta as diferenças entre os corpos como propulsoras da criação. Temos o exemplo radical de Sílvia Wolff, que narra em sua tese o seu processo de "aceitação como bailarina que dança com meu corpo atual" (Wolff, 2010, p. 91), do corpo depois de um AVC que comprometeu os movimentos de todo o seu lado esquerdo do corpo. Ao longo do processo de reabilitação, no qual ela não abandonou a dança, pelo contrário, ela vai modificando seu modo de viver o movimento e o seu conhecimento de si: antes era um conhecimento por via da imagem do espelho, depois, "[...] um exercício de reconhecer e aceitar meu corpo e minha existência, de redefinir tempo, espaço e identidade, de lidar com a história de uma dança que carrego no corpo, de abordar questões e diferença" (Wolff, 2010, p. 92). Nesse seu processo está presente a prática da técnica Feldenkrais, técnica de release e outras práticas de dança com base em princípios da educação somática (Wolff, 2010, p. 56-57).

Algumas autoras entendem que as práticas somáticas podem ser concebidas como técnicas de si: que permitem "[...] opor o discurso dominante e dar suporte às transformações das relações de poder na dança" (Fortin et al., 2009, p. 50, tradução minha) ${ }^{10}$; "capazes de colocar o poder em jogo [...], colocando a primazia do processo poético-pedagógico naquele que experimenta" (Rosa, 2016b, p. 8).

A partir de seu estudo sobre a Antiguidade, Foucault (1998) estudou o que chamou de tecnologias do eu, ou tecnologias de si: práticas ativas que produzem uma relação do sujeito consigo mesmo, como sujeito ético. Tratam-se de práticas que possibilitam a constituição de um modo de existência, que implicam necessariamen-

\footnotetext{
${ }^{9}$ No original, em inglês: "[...] there is a lot of pressure for many Brazilian dancers and non-dancers to conform to the external image of the body provided by the media, their body being exposed all year long to the gaze of others in the all-year sun along the beaches in urban areas" (Fortin, 2002, p. 133). (Tradução nossa)

10 No original, em inglês: "[...] somatic education can be conceived of a technology of the self that counteracts the dominant discourse and supports a transformation of the power relations in dance" (Fortin et al., 2009, p. 50). (Tradução nossa)
} 
te uma ética, uma conduta, um modo de agir "em referência aos elementos prescritivos que constituem o código" (Foucault, 1998, p. 27). Com efeito, são práticas que implicam a constituição de si como sujeito moral.

Pensar as práticas somáticas como técnicas de si é também considerar que tais práticas relativizam o código, pois relativizam a norma que estabelece o corpo ideal, a normalização produzida pelas tecnologias da biopolítica. Assim, ao realizar práticas na perspectiva da educação somática, há um processo de atuação sobre si mesmo, no qual a pessoa realiza um trabalho sobre si que passa pela produção de uma relação de si com os códigos.

Assim, essas práticas pressupõe a construção de conhecimento do próprio corpo por via de um processo investigativo, pois o que é o nosso corpo não é dado. $O$ que é o nosso corpo é, a um só tempo, aquilo que é percebido e aquilo que é reelaborado. São práticas relacionadas à produção de si mesmo, aos modos de nos subjetivarmos a nós mesmos.

O caso de Sílvia Wolff mostra um processo de transição de um conjunto de práticas que vincula a si mesma com um padrão de corpo ideal (a um código de normalização rígido) ${ }^{11}$, para um conjunto de práticas que relativiza a normalização.

Jill Green denomina teoria social somática (social somatic theory) um corpo literário criado por alguns teóricos e educadores que escaparam da tendência em focar na experiência interna e deslocaram seus estudos para uma esfera sócio-política macro. Desde esse lugar, acrescentam questões sobre como nossos corpos e experiências somáticas são inscritas pela cultura em que vivemos (Green, 2002-2003, p. 102). A autora lembra-se do perigo de as práticas somáticas levarem ao individualismo e nos hipnotizarem da relação com o mundo, apontado por Don Hanlon Johnson (1992).

Se é investindo no corpo que o poder atua, é no trabalho com o corpo que podemos encontrar modos de resistir ao poder dominante. "De acordo com Moshe Feldenkrais, os indivíduos não podem experienciar a liberdade e ser totalmente criativos a menos que sejam aptos a reconhecer seus hábitos de percepção e atuar sobre eles" (Fortin et al., 2009, p. 49) ${ }^{12}$. Porém, segundo Green, Foucault suspeitaria de práticas que trabalham pedagogicamente através do corpo e “[...] seria cauteloso com as práticas somáticas e trabalhos criativos porque ele aponta que a experiência é baseada em como nossas percepções são socialmente construídas" (Green, 2002-2003, p. 104)13.

A tensão ao compor um currículo para a dança expõe as escolhas políticas da professora, que se dão no âmbito do micro (nas relações entre professora, alunos e escola), em conexão com a macropolítica e seu modo de atuar diretamente sobre cada indivíduo.

\footnotetext{
11 Em uma pesquisa com cinco discentes de um curso de graduação em dança, Jill Green identifica que as alunas trazem internalizada a necessidade de alcançar a forma do corpo perfeito idealizado pela dança. "Para elas, tornar-se o corpo ideal da dança era um caminho para a felicidade e a perfeição" (Green, 2002-2003, p. 118, tradução minha), um modo de produzirem a si mesmas tal como a norma. Green aponta para as sérias disfunções alimentares produzidas pela internalização dessa norma. No original, em inglês: "For them, the ideal dance body was a way to happiness and perfection" (Green, 2002-2003, p. 118). (Tradução nossa)

12 No original, em inglês: "According to Moshe Feldenkrais, individuals cannot experience freedom and be fully creative unless they are able to recognize their perceptual habits and act upon them" (Fortin et al., 2009, p. 49). (Tradução nossa)

13 No original, em inglês: "He would be cautious about somatic practices and creative work because of his claim that experiences is based on how our perceptions have been socially constructed" (Green, 2002-2003, p. 104). (Tradução nossa)
} 


\section{Considerações Finais}

Este texto apresentou a ideia de que práticas a partir da perspectiva da educação somática demandam um tipo de estrutura física e um tipo de conduta da professora, que produzem o ambiente para a construção de um estado corporal, o qual permite aos alunos e alunas acessarem um tipo de conhecimento. Também acata a definição de currículo como o conjunto formado pelo modo de ensinar, o modo de aprender e os objetos a conhecer; guiado pelo tipo de sujeito que se almeja produzir.

No currículo intencionado pela professora Adriana, seus alunos e alunas devem ser protagonistas nos caminhos daquilo que irão se tornar. Ela escolhe práticas que possam subsidiar essa construção. Colhe essas práticas na sua experiência de "dança como arte". Definitivamente é uma escolha política, que implica resistir à máquina do neoliberalismo. Tais práticas almejam corpos sujeitos que possam resistir ao discurso dominante, que produz o corpo hiperproduzido e fracassado.

Importante ressaltar que o protagonismo que se fala aqui é diferente daquele de algumas enunciações que têm impregnado o campo da educação, relacionadas à produção do líder, sujeito autônomo, vencedor, em conexão com o sistema da meritocracia. A trama que dificulta a perspectiva da educação somática na composição do currículo das escolas passa, portanto, por interdição dos saberes dos outros discursos, diferentes do dominante.

O currículo é, portanto, campo de luta política. Quando o corpo está no centro do currículo, se evidencia o corpo como lugar dessa luta.

\section{Referências}

BRASIL. LDB. N. 9.394 de 20 de dezembro de 1996. Estabelece as Diretrizes e Bases da educação Nacional. Diário Oficial da República Federativa do Brasil, Brasília, DF, v. 23, 1996.

BRASIL. Lei no 13.278, de 2 de maio de 2016. Altera o I 60 do art. 26 da Lei no 9.394, de 20 de dezembro de 1996, que fixa as diretrizes e bases da educação nacional, referente ao ensino da arte. Diário Oficial da República Federativa do Brasil, Brasília. 2016.

BRASIL. Ministério da Educação. Base Nacional Comum Curricular. Brasília: MEC, 2017. Disponível em: <http://basenacionalcomum.mec.gov.br/>. Acesso em: 15 jun. 2017.

BRASIL. Secretaria de Ensino Fundamental. Parâmetros Curriculares Nacionais. Brasília: MEC, 1997.

DOMENICl, Eloisa. O encontro entre dança e educação somática como uma interface de questionamento epistemológico sobre as teorias do corpo. Pro-Posições, Campinas, v. 21, n. 2 (62), maio/ago. 2010, p. 69-85.

DOSSIÊ ADRIANA. Transcrição das aulas e entrevistas. Arquivo confidencial não publicado. 122 f. 2016. 
FERNANDES, Ciane. Quando o Todo é mais que a Soma das Partes: somática como campo epistemológico contemporâneo. Revista Brasileira de Estudos da Presença, Porto Alegre, v. 5, n.1, 2015, p. 9-38. Disponível em: <http://seer.ufrgs.br/index.php/ presenca/article/view/47585/32478>. Acesso em: 01 out. 2015.

FERNANDES, Silvia. Performatividade e Gênese da Cena. Revista Brasileira de Estudos da Presença, Porto Alegre, v. 3, n. 2, maio/ago. 2013, p. 404-419. Disponível em: <http:// seer.ufrgs.br/index.php/presenca/article/view/38137>. Acesso em: 05 set. 2015.

FORTIN, Sylvie. Living in Movement: development of somatic practices in different cultures. Journal of Dance Education, v. 2, n. 4, 2002, p. 128-136.

FORTIN, Sylvie; LONG, Warwick; LORD, Madeleine. Three voices: Researching how somatic education informs contemporary dance technique classes. Research in Dance Education, v. 3, n. 2, 2002, p. 155-179.

FORTIN, Sylvie; VIEIRA, Adriane; TREMBLAY, Martyne. The experience of discourses in dance and somatics. Journal of Dance and Somatic Practices, v. 1, n. 1, 2009, p. 47-64.

FOUCAULT, Michel. Microfísica do Poder. Organização e Tradução: Roberto Machado. Rio de Janeiro: Graal. 1979.

FOUCAULT, Michel. História da sexualidade 2: o uso dos prazeres. Rio de Janeiro: Graal, 1998.

FOUCAULT, Michel. O Sujeito e o Poder. In: DREYFUS, Hubert; RABINOW, Paul. Michel Foucault uma Trajetória Filosófica: para além do estruturalismo e da hermenêutica. Rio de Janeiro: Forense Universitária, 2010. p. 273-295.

FUÃO, Anna Schumacher Eder. Performances de Tempos e Espaços na Escola: um estudo com professoras da rede pública. Porto Alegre: UFRGS, 2015. 107 f. Dissertação (Mestrado em Educação) - Universidade Federal do Rio Grande do Sul, Porto Alegre, 2015.

GEHRES, Adriana de Faria. Corpo-Dança-Educação: na contemporaneidade ou na construção de corpos fractais. Lisboa: Instituto Piaget, 2008.

GREEN, Jill. Foucault and the training of docile bodies in dance education. Arts and Learning Research Journal, v. 19, n. 1, 2002-2003, p. 99-125.

HARDT, Michael; NEGRI, Antonio. A produção Biopolítica. In: PARENTE, André. Tramas da Rede: novas dimensões filosóficas, estéticas e políticas da comunicação. Porto Alegre: Sulina, 2010.

ICLE, Gilberto. Problemas teatrais na educação escolarizada: existem conteúdos em teatro? Urdimento, Florianópolis, v. 2, n. 17, 2011, p. 70-77. 
KASTRUP, Virgínia; PASSOS, Eduardo. Cartografar é traçar um plano comum. Fractal, Niterói, v. 25, n. 2, maio/ago. 2013, p. 263-280. Disponível em: <http://www.uff.br/ periodicoshumanas/index.php/Fractal/article/view/1109>. Acesso em: 15 abr. 2015.

MILLER, Jussara. Qual é o corpo que dança? Dança e educação somática para adultos e crianças. São Paulo: Summus, 2012.

PÁL PELBART, Peter. Entrevista. 2014. Disponível em: <https://www.sescsp.org.br/ online/artigo/8624_PETER+PAL+PELBART>. Acesso em: 15 maio 2017.

PINEAU, Elyse Lamm. Pedagogia crítico-performativa: encarnando a política da educação libertadora. In: PEREIRA, Marcelo de Andrade. Performance e Educação: (des) territorializações pedagógicas. Santa Maria: UFSM, 2013. p. 37-58.

ROSA, Tatiana Nunes da. O termo "educação somática" perspectivado pela criação em dança no Brasil. In: VIEIRA, Alba Pedreira; BECKER, Daniel (Org.). Caderno do GIPE-CIT, Salvador, UFBA/PPGAC, ano 20, n. 36, 2016a, p. 86-104.

ROSA, Tatiana Nunes da. Movimento - Hiato - Palavra: o estatuto da sensação e a dança. In: REUNIÃO CIENTÍFICA REGIONAL DA ANPED SUL, 11., 2016, Curitiba. Anais... Curitiba, $2016 \mathrm{~b}$. SILVA, Ana Márcia. Corpo, Ciência e Mercado: reflexões acerca da gestação de um novo arquétipo de felicidade. Campinas: Autores Associados; Florianópolis: Editora da UFSC, 2001.

SILVA, Tomaz Tadeu da. Documentos de Identidade: uma introdução às teorias do currículo. Belo Horizonte: Autêntica, 2007.

SMITH-AUTARD, Jacqueline M. The Art of Dance in Education. London: A \& C Black, 2002.

SMITH-AUTARD, Jacqueline M. Dance Composition: a practical guide to creative success in dance making. London: A \& C Black, 2004.

SOUZA, Andrea Bittencourt de. Narrativas sobre o ensino da dança: caminhos tramados e traçados em escolas do Rio Grande do Sul. Porto Alegre: UFRGS, 2015. 201 f. Tese (Doutorado em Educação) - Universidade Federal do Rio Grande do Sul, 2015.

TODD, Mabel Elsworth. The Thinking Body: a study of the balancing forces of dynamic man. Princeton Book Company Pub, 1937.

WOLFF, Silvia Susana. Momento de transição: Em Busca de uma Nova Eu Dança. Campinas: UNICAMP, 2010. 126 f. Tese (Doutorado em Artes) - Universidade Estadual de Campinas, Campinas, 2010. 